\title{
PUSAT OLEH - OLEH KALIMANTAN SELATAN DI BANJARMASIN
}

\author{
Agusti Dwi Asdani \\ Program Studi Arsitektur Fakultas Teknik Universitas Lambung Mangkurat \\ agustidwiasdani1996@gmail.com \\ Dila Nadya Andini \\ Program Studi Arsitektur Fakultas Teknik Universitas Lambung Mangkurat \\ dila.andini@ulm.ac.id
}

\begin{abstract}
ABSTRAK
Perancangan Pusat Oleh - Oleh Kalimantan Selatan dilatarbelakangi oleh banyaknya wisatawan yang berkunjung ke Kalimantan Selatan khususnya Banjarmasin. Salah satu kebutuhan yang berpengaruh dari peningkatan wisatawan adalah kebutuhan wisatawan akan produk oleh - oleh khas daerah. Toko oleh oleh yang ada di Banjarmasin saat ini kurang representatif sehingga keberadaan pusat oleh - oleh yang menjual macam - macam produk khas Kalimantan Selatan dalam satu tempat yang memiliki ciri khas lokal agar wisatawan tidak hanya berbelanja tetapi juga mendapatkan pengalaman berwisata. Metode penyelesaian masalah yang diterapkan adalah metode Arsitektur Metafora yang merujuk pada tahapan desain bangunan sebagai karakter tertentu dari sebuah bentukan atau benda yang khas dengan Banjarmasin. Konsep perancangan menerapkan konsep one stop shopping dimana pusat oleh - oleh mampu mewadahi berbagai macam produk khas Kalimantan Selatan dalam satu tempat. Hasil rancangan berupa desain bangunan yang dapat menjadi salah satu ikon kota Banjarmasin yang mewadahi fasilitas berbelanja oleh-oleh dalam satu tempat.
\end{abstract}

Kata Kunci: oleh-oleh, pusat oleh - oleh, metafora, one stop shopping

\begin{abstract}
The design of South Kalimantan Souvenir Center is motivated by the number of tourists visiting South Kalimantan, especially Banjarmasin. One of the influential needs of the increase in tourists is the need for local specialties. Souvenir shops in Banjarmasin currently are less representative, so the existence of a souvenir center that sells a variety of South Kalimantan specialty products in one place that has local characteristics so that tourists not only shop but also get a tour experience. The problem solving method applied is the Metaphor Architecture method which refers to the building design stage as a certain character from a formation or object that is unique to Banjarmasin. The design concept applies the concept of one stop shopping where this souvenir center is able to accommodate a variety of typical products of South Kalimantan in one place. The result of the design is in the form of a building design that can become one of the icons of the city of Banjarmasin that accommodates souvenir shopping facilities in one place.
\end{abstract}

Keywords: souvenirs, souvenirs center, metaphors, one stop shopping. 


\section{PENDAHULUAN}

Banjarmasin merupakan lbu kota Provinsi Kalimantan Selatan yang memiliki luas $98,46 \mathrm{~km}^{2}$. Banjarmasin dikenal dengan julukannya sebagai Kota Seribu Sungai yang mencerminkan ciri khas kota dengan banyaknya jaringan sungai. Pinggiran kota dengan pemandangan sungai serta wisata susur sungai menggunakan perahu klotok menjadi daya tarik utama Kota Banjarmasin. Selain itu, banyaknya destinasi wisata yang tersebar di Kalimantan Selatan juga menjadi salah satu faktor utama banyaknya wisatawan yang berkunjung ke Kota Banjarmasin. Peningkatan ini dapat dilihat dari data kunjungan wisatawan dalam negeri maupun luar negeri di Kalimantan Selatan oleh Dinas Pariwisata (2019) pada Gambar 1 di bawah.

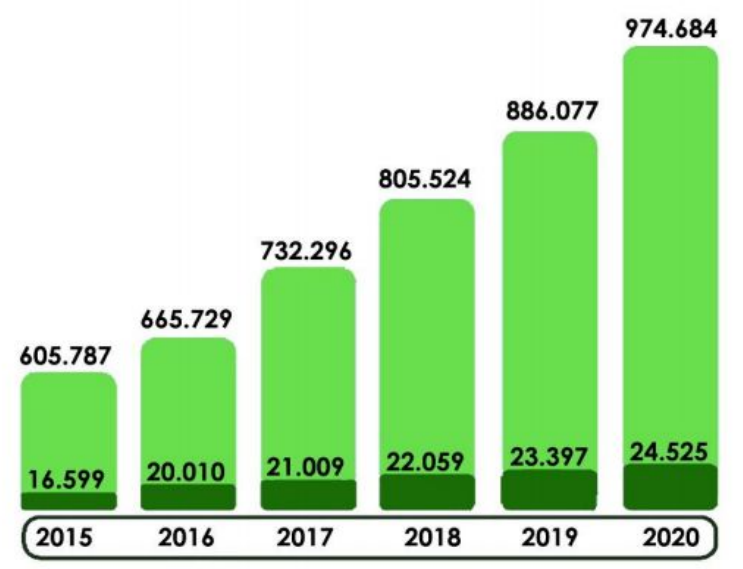

\section{Wisatawan Dalam Negeri \\ Wisatawan Luar Negeri}

Data kunjungaan wisatawan tahun 2015 - 2016 dan prediksi sampai 2020 By kalsel (6)

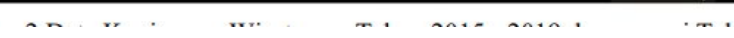

Gambar 1. Data Kunjungan Wisatawan Tahun 2015 - 2016 dan prediksi sampai Tahun 2020

Dari data tersebut, prediksi sampai tahun 2020 jumlah wisatawan yang berkunjung mengalami peningkatan. Melihat kecenderungan tersebut, Banjarmasin perlu menangkap peluang dengan menyediakan pusat oleh-oleh yang mampu memenuhi kebutuhan wisatawan dan bisa menjadi wadah untuk memperkenalkan dan memasarkan produk lokal. Saat ini, keberadaan pusat oleh-oleh di kota Banjarmasin masih belum tersentralisasi sehingga para wisatawan membutuhkan banyak waktu untuk berburu oleh-oleh. Adapun beberapa toko oleh-oleh yang ada di Banjarmasin adalah sebagai berikut.

\section{- Toko Galuh Banjar}

Toko ini merupakan salah satu toko oleh-oleh terlengkap yang ada di Banjarmasin, bertempat di Jl. S Parman No. 5, kec. Banjarmasin Barat, kota Banjarmasin.

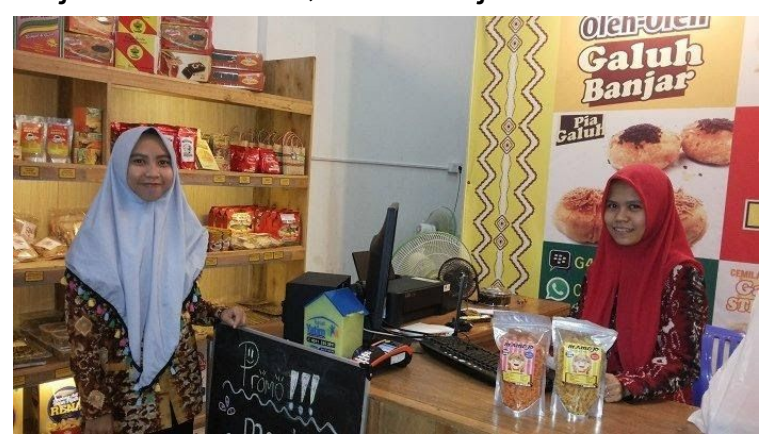

Gambar 2. Toko Oleh - Oleh Galuh Banjar

- Toko Andalas

Toko ini terletak di Jl. Perintis Kemerdekaan Rt. 22 no. 12, kel. Pasar lama, kec. Banjarmasin Tengah, kota Banjarmasin.

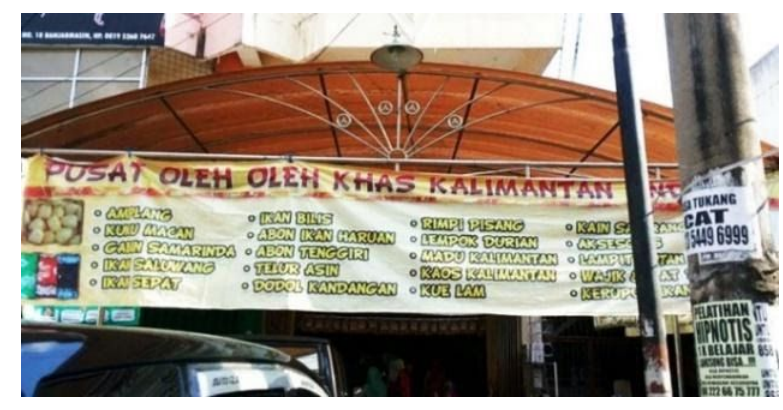

Gambar 3. Toko Andalas 
Berdasarkan hasil pengamatan, keberadaan pusat oleh-oleh yang sudah ada di Banjarmasin memiliki kelebihan dan kelemahan. Kelemahan pada toko oleh - oleh kebanyakan hanya menyediakan satu kategori oleh-oleh, baik makanan atau souvenir. Selain itu, area kasir kurang memadai sehingga banyaknya wisatawan yang berbelanja merasa tidak nyaman akibat antrian saat pembayaran. Lahan parkir pun terbatas /sempit. Secara desain arsitektur, toko oleh oleh yang ada tidak menarik karena hanya memanfaatkan kios dan rumah toko (ruko) sebagai tempat penjualan.

Fungsi pusat oleh - oleh seharusnya tidak sekadar sebagai tempat berbelanja, tetapi mampu menjadi wadah rekreasi yang mencerminkan wajah kota bagi wisatawan maupun warga setempat sehingga pengalaman berbelanja dan rekreasi menjadi menyenangkan. Oleh sebab itu, Banjarmasin memerlukan pusat oleh-oleh yang secara arsitektural mampu memberikan pengalaman berbelanja yang menyenangkan dengan berbagai macam produk oleh-oleh khas Kalimantan Selatan dalam satu lokasi sehingga dapat mempermudah wisatawan kebutuhan berbelanja oleh-oleh sekaligus rekreasi selama berwisata di kota Banjarmasin.

Berdasarkan uraian di atas, permasalahan perancangan pusat oleh-oleh Kalimantan Selatan dirumuskan sebagai berikut: Bagaimana rancangan Pusat Oleh-oleh Kalimantan Selatan yang mampu mewadahi pelayanan berbelanja dalam satu tempat serta dapat menarik wisatawan untuk mengunjungi pusat oleh-oleh tersebut?

\section{TINJAUAN PUSTAKA}

\section{A. Tinjauan Pusat Oleh - Oleh}

Menurut Kamus Besar Bahasa Indonesia (KBBI), pusat adalah tempat yang letaknya di tengah, pokok atau pangkal yang menjadi tumpuan (berbagai urusan, hal dan sebagainya). Sedangkan, oleh-oleh/cendera mata adalah sesuatu yang dibawa dari bepergian. Cendera mata bisa berupa apa saja, namun cedera mata yang khas biasanya berupa kain/pakaian lokal, kerajinan tangan, makanan khas, dan lain-lain.

Jadi, pusat oleh - oleh merupakan tempat yang menyediakan beragam jenis oleh-oleh atau produk khas suatu daerah yang biasa dijadikan buah tangan atau kenang-kenangan untuk dibawa pulang.

\section{B. Tinjauan Konsep One Stop Shopping}

Konsep yang diangkat untuk rancangan pusat oleh-oleh ini ialah One Stop Shopping. Kata One Stop diartikan sebagai kegiatan yang berkelanjutan, sedangkan shopping yang diartikan "belanja" memiliki arti sesuatu atau perbuatan yang disenangi seseorang terhadap apa yang mereka inginkan dengan cara membelinya. Melalui penerapan konsep ini, wisatawan yang datang diharapkan dapat membeli semua kebutuhan untuk oleh - oleh mereka, dari berbelanja jajanan khas, kerajinan/aksesoris dan sekaligus wisata kuliner khas Kalimantan Selatan di satu lokasi. Konsep ini juga membantu memudahkan wisatawan yang mungkin hanya punya sedikit waktu kunjungan untuk mendapatkan pengalaman yang maksimal.

\section{METODE PERANCANGAN}

Metode yang digunakan adalah metode metafora abstrak (intangible metaphors). Metafora mengidentifikasikan hubungan antara benda dimana hubungan tersebut lebih bersifat abstrak daripada nyata serta mengidentifikasikan pola hubungan yang sejajar. Metafora menggunakan kata senada dengan "bagaikan" atau "seperti" untuk mengungkapkan suatu hubungan. Intangible metaphors didasari oleh suatu konsep, ide, hakikat manusia dan nilai-nilai seperti 
individualisme, naturalisme, komunikasi, tradisi dan budaya. Dengan metafora seorang perancang dapat berkreasi dan bermain dengan imajinasinya untuk diwujudkan dalam bentuk karya arsitektur.

\section{PEMBAHASAN}

\section{A. Konsep Program}

Tujuan dari perancangan ini adalah menjadikan pusat oleh-oleh yang mampu mengenalkan daerah Kalimantan Selatan kepada para wisatawan dengan cara mengenalkan jajanan khas daerah, kerajinan khas daerah, agar menjadi nilai jual yang tinggi terhadap nilai khas kebudayaan Kalimantan selatan.

Konsep One Stop Shopping (berbelanja dalam satu pemberhentian) yaitu konsep yang memberikan ruang berbelanja dalam satu pemberhentian sehingga dapat memberikan kenyamanan kepada wisatawan dalam memenuhi kebutuhan berbelanja sekaligus berwisata. Sedangkan, arsitektur metafora diterapkan dalam proses pembentukan gubahan massa/bangunan, aspek interior, eksterior dan lanskap.

\section{B. Penerapan Metafora dalam Desain}

Banjarmasin dijuluki dengan kota seribu sungai. Selain itu, Banjarmasin terkenal dengan wisata sungainya yaitu pasar terapung, dimana para pedagang menggunakan perahu atau yang disebut dengan jukung, sebagai sarana untuk berjualan di pasar terapung sungai barito.

Sungai Barito sendiri dulunya merupakan akses utama perekonomian warga Banjarmasin dengan menggunakan jukung sebagai transportasi jual beli khususnya di pasar terapung. Jadi, ada 2 poin yang diambil dari penjelasan di atas untuk metafora bentuk bangunan pusat oleh-oleh. Pertama, sungai barito; dan kedua jukung sebagai sarana untuk masyarakat beraktivitas di Sungai Barito.

Bentuk bangunan mentransformasikan alur sungai Barito (Gambar 4). Kemudian, gubahan bentuk awal tersebut ditransformasi lebih lanjut dengan ide bentuk jukung sebagai detail fasade bangunan (Gambar 5).

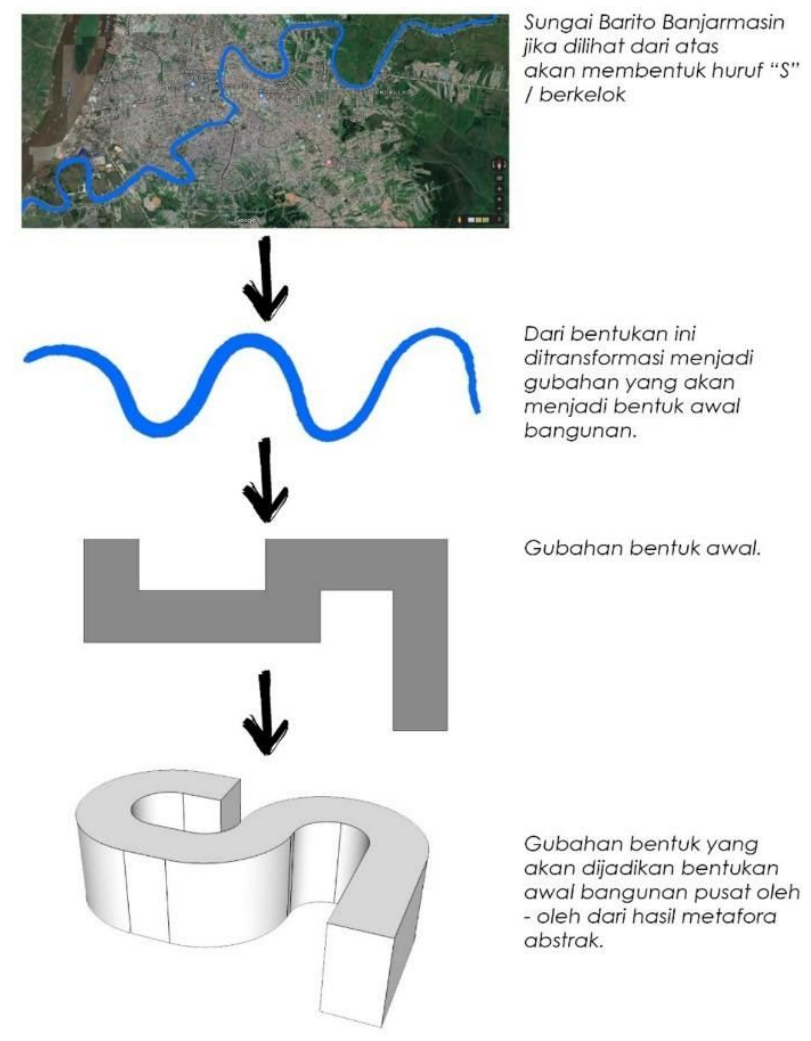

Gambar 4. Metafora Bentuk Dasar Bangunan

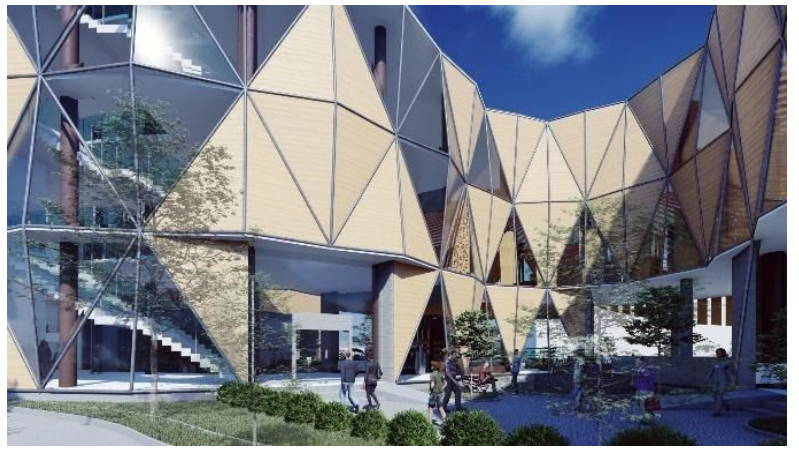

Gambar 5. Transformasi Detail Fasade

Hal ini menghasilkan bentuk denah berkelok menyerupai huruf $\mathrm{S}$; luwes tanpa sudut (Gambar 6) dan detail fasad yang 
ditransformasikan dari bentuk jukung (Gambar 7).

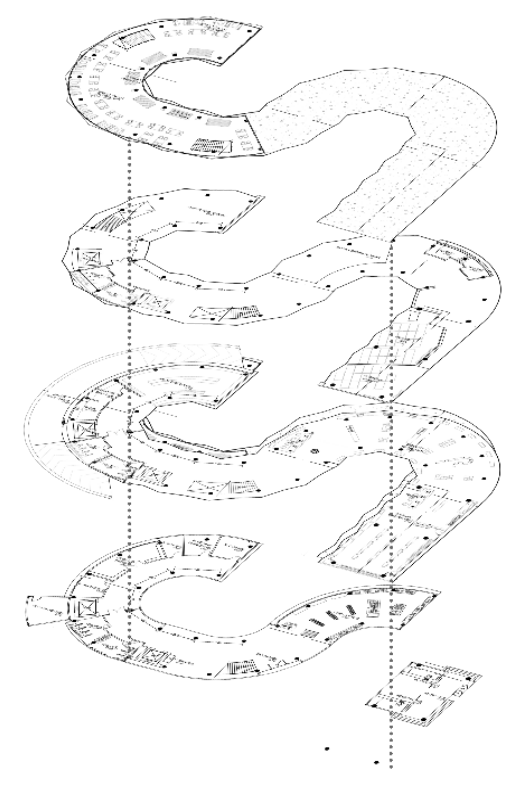

Gambar 6. Bentuk Denah Bangunan

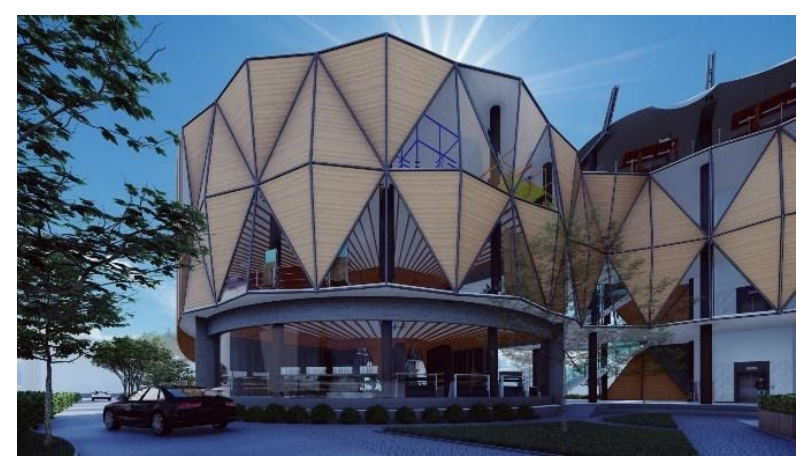

Gambar 7. Detail Fasade Bangunan

\section{Penerapan Konsep One Stop Shopping}

Penerapan konsep one stop shopping difokuskan dalam penyediaan fasilitas, tata ruang dan desain interior. Kelengkapan fasilitas menjadi hal yang utama dalam konsep one stop shopping. Bangunan dirancang terdiri dari 3 lantai dan 1 rooftop menyesuaikan peraturan koefisien dasar bangunan dan koefisien dasar hijau pada tapak. Zona ruang dibedakan tiap lantai bangunan. Lantai 1 berfungsi sebagai display kue/jajanan khas daerah Kalimantan Selatan, ruang pengelola dan servis/gudang utama penyimpanan produk (Gambar 8).
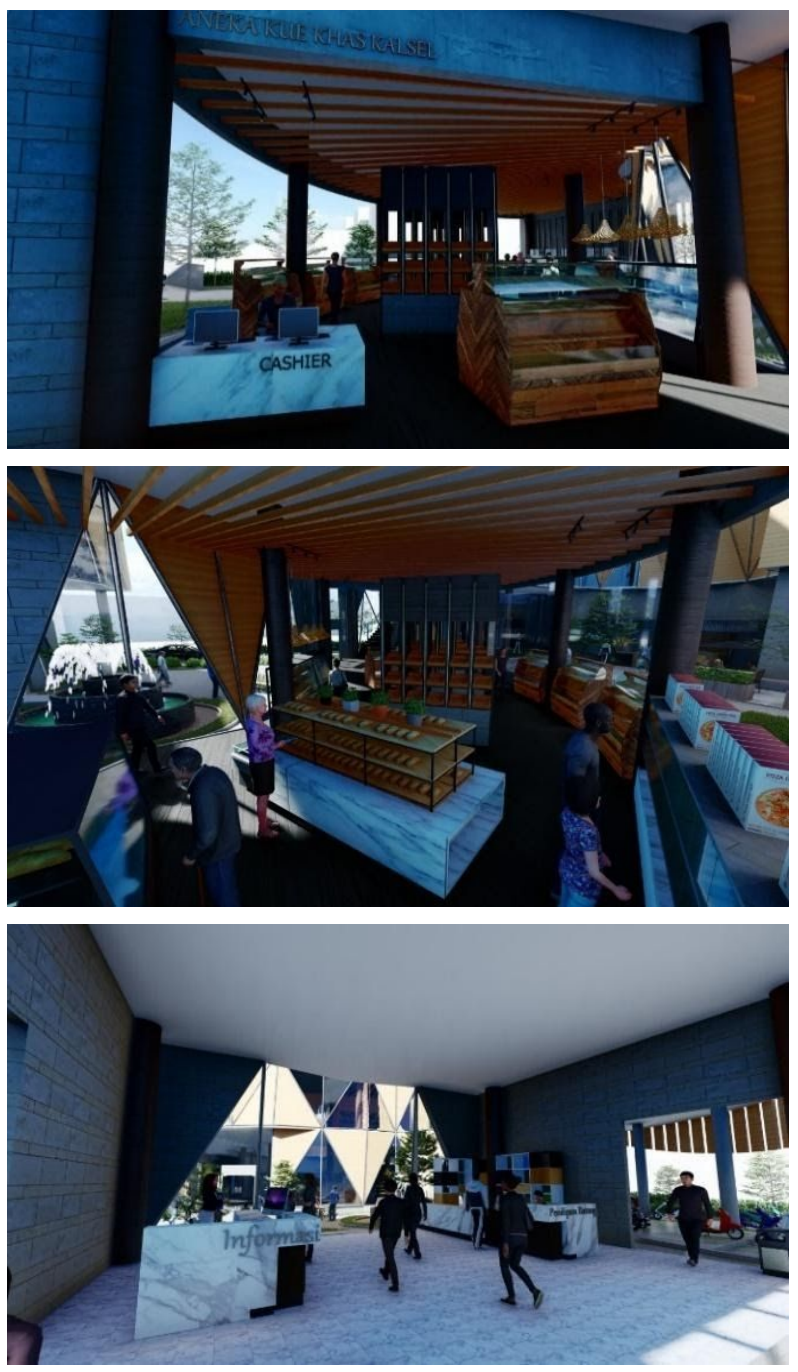

Gambar 8. Interior Lantai 1: Lobi dan Area Kue

Lantai 2 terdiri dari area drive thru, display kerajinan dan sasirangan (Gambar 9). Pada lantai 3 ada dapur foodcourt dan zona penunjang berupa indoor playground/taman bermain anak dan mushola. Sedangkan, rooftop digunakan untuk area foodcourt kuliner khas Kalimantan Selatan (Gambar 10). 
Unsur-unsur lokal diterapkan pada material dan detail ruangan. Pada area outdoor, disediakan taman 'mawarung'. Fungsi yang diadaptasi dari kebiasaan orang-orang Banjar yang suka berkumpul dan bersosialisasi di area-area makan/warung (Gambar 11).
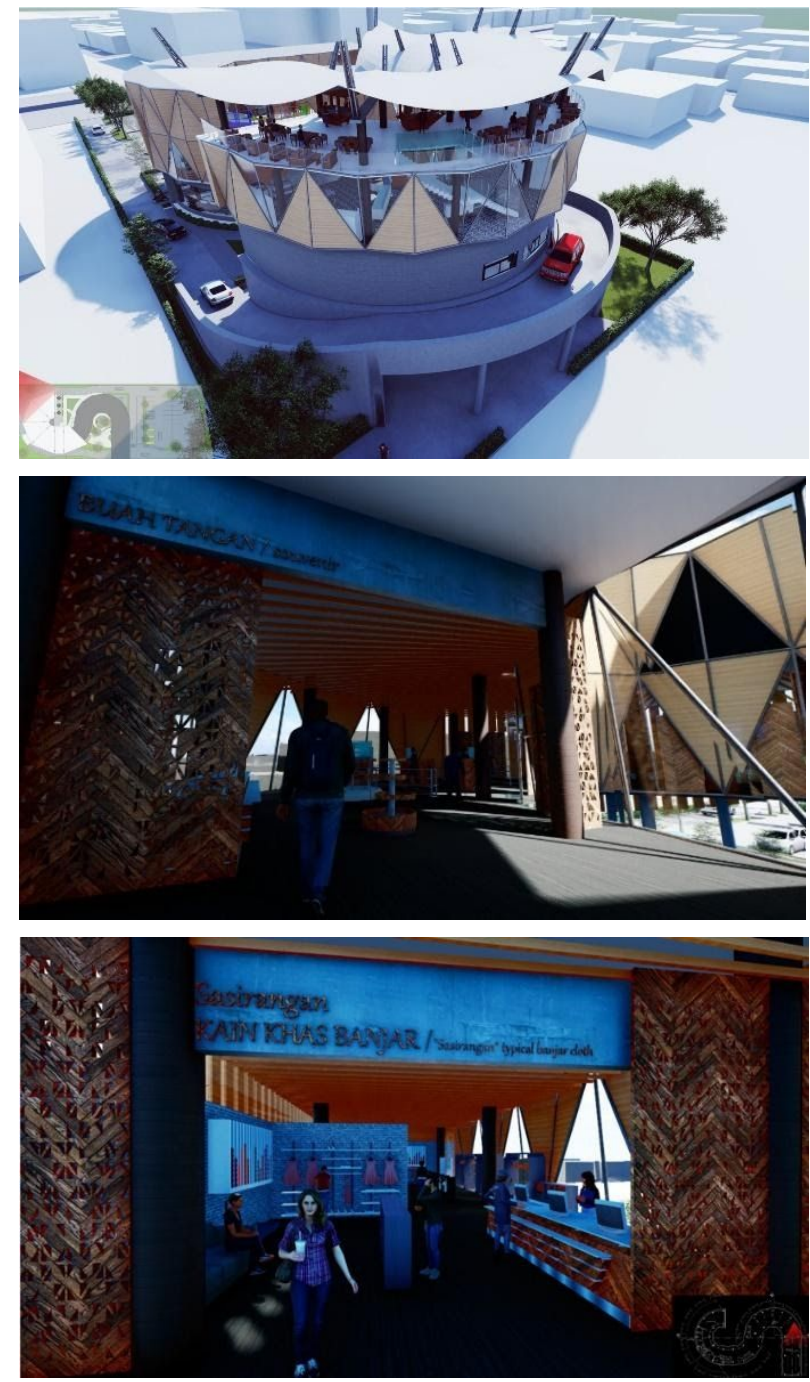

Gambar 9. Interior Lantai 2: area drive thru, display kerajinan dan sasirangan
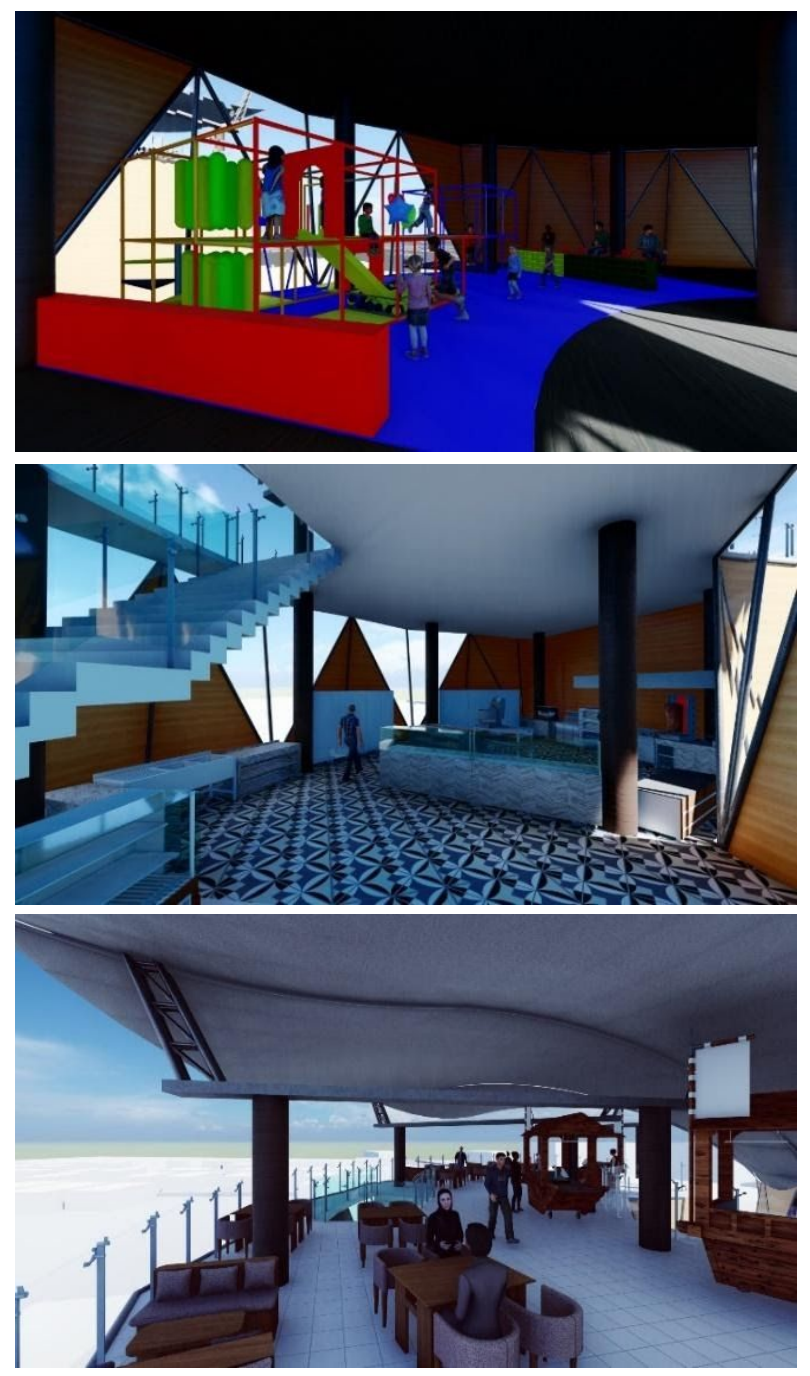

Gambar 10. Interior Lantai 3 dan Rooftop

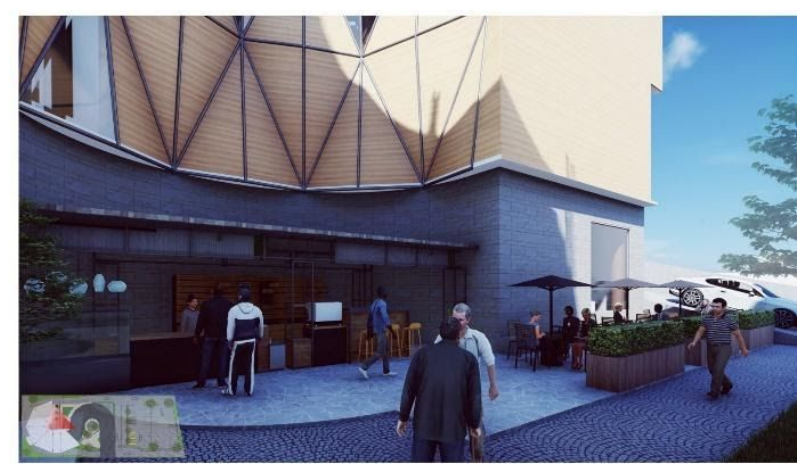

Gambar 11. Taman Mawarung

\section{PENUTUP}

Pusat Oleh - oleh Kalimantan Selatan dirancang dengan menerapkan konsep One 
Stop Shopping dimana bangunan ini menyediakan produk-produk khas Kalimantan selatan dalam satu tempat pemberhentian sehingga memudahkan wisatawan yang berkunjung untuk mendapatkan cinderamata khas dalam satu area. Perancangan menerapkan metode metafora dalam penyelesaian masalah yang merujuk ke tahapan bentukan bangunan/tampilan bangunan yang bercirikan Kota Banjarmasin sehingga desain bangunan dapat menjadi salah satu ikon kota tujuan wisata Kalimantan Selatan, khususnya Banjarmasin.

HASIL DESAIN

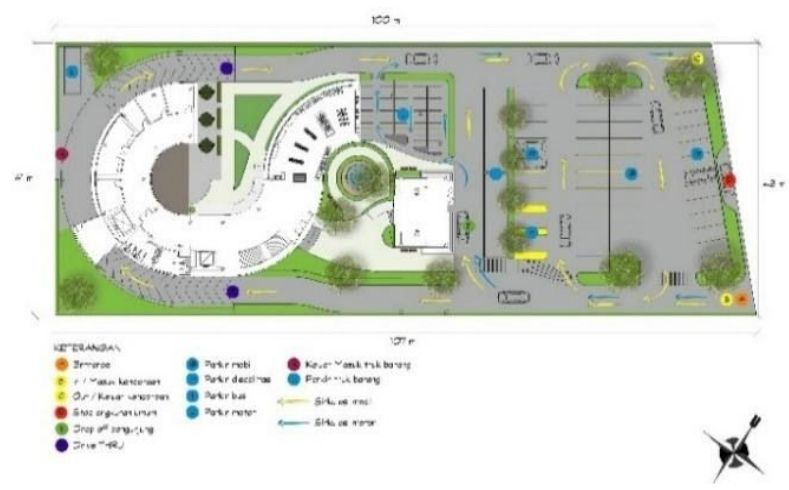

Gambar 12. Rencana Tapak
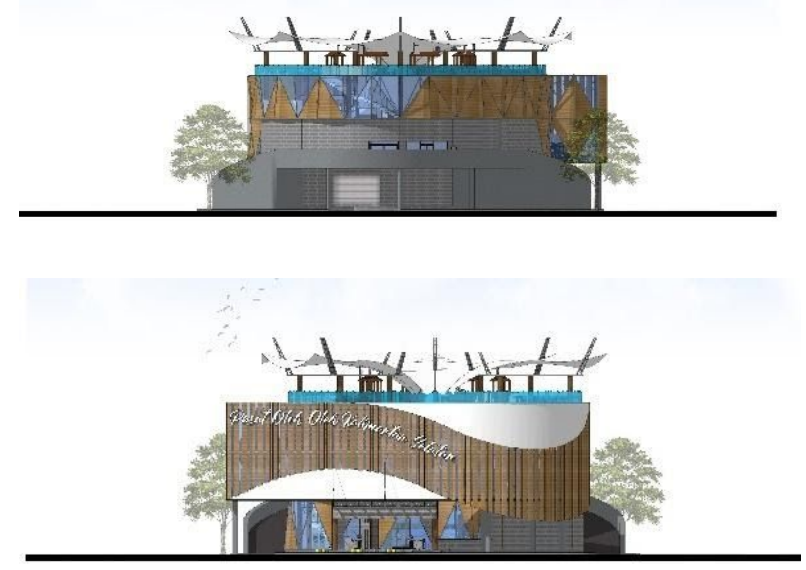

Gambar 13. Rencana Tampak
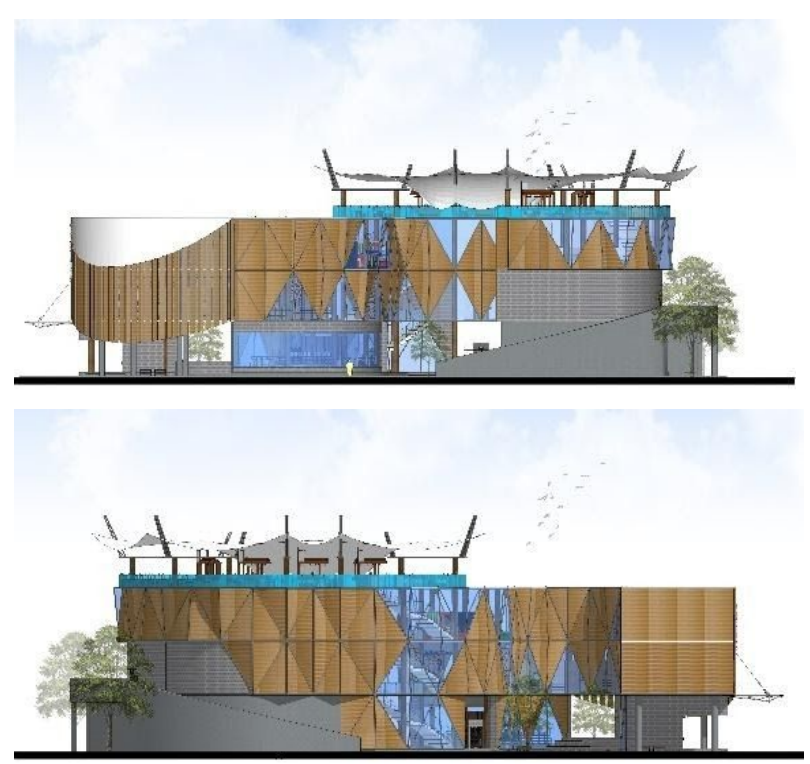

Gambar 14. Tampak Samping
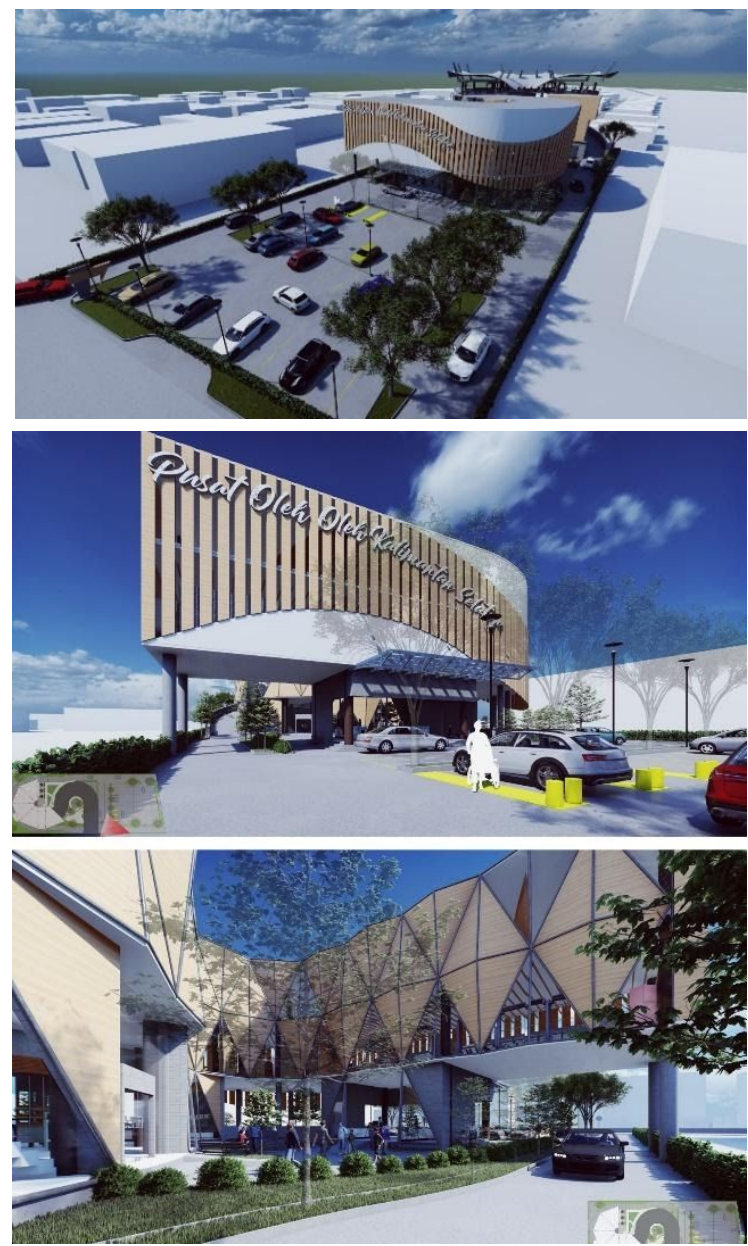

Gambar 15. Perspektif Eksterior 


\section{DAFTAR PUSTAKA}

BPS (Badan Pusat Statistik), k. B. (2018). Kota Banjarmasin Dalam Angka. Banjarmasin: BPS Kota Banjarmasin.

Broadbent. (1988). Arsitektur Metafora. Arsitektur Metafora.

Dinas Pariwisata. (2019, juli 15). wonderfull kalsel. Retrieved from Dinas Pariwisata Provinsi Kalimantan Selatan: Dinas Pariwisata Provinsi Kalimantan Selatan Jenks, C. (1991). The Language of Post Modern. Rizzoli: 15 agustus 1991.

KBBI, K. B. (2007). Pusat oleh-oleh.

Kotler. (2004). One stop shopping. sarjanaku.com. Retrieved from sarjanaku.com. 